\title{
Correction to letter: Image-guided thermal ablation of benign thyroid nodules
}

\author{
Claudio M. Pacella ${ }^{1}$ (1)
}

Published online: 21 February 2018

(c) Società Italiana di Ultrasonologia in Medicina e Biologia (SIUMB) 2018

Correction to: Journal of Ultrasound (2017) 20:347-349

https://doi.org/10.1007/s40477-017-0269-y

The original version of this article unfortunately was incorrect. The correct title should read: "Comment to article: "Image-guided thermal ablation of benign thyroid nodules" by A. Mainini, et al. J Ultrasound (2017) https://doi. org/10.1007/s40477-016-0221-6".

The original article can be found online at https://doi.org/10.1007/ s40477-017-0269-y.

Claudio M. Pacella

claudiomauriziopacella@gmail.com

1 Department of Diagnostic Imaging and Interventional Radiology, Regina Apostolorum Hospital, Albano Laziale, 00041 Rome, Italy 